now published is only the first of a series on the same subject with which he will enrich the literature of the science.

ARCH. GEIKIE

\section{HUMAN MORPHOLOGY}

Human Morphology; a Treatise on Practical and Applied Anatomy. By Henry Albert Reeves. Vol. I. The Limbs and Perinæum. (London: Smith, Elder, and Co., I 882.)

$7 \mathrm{HE}$ author of this work is evidently very ambitious. 1 In his preface he tells us that his primary wish was to produce a treatise in which he would deal thoroughly with the anatomy of man, and then compare his structure with that of other vertebrates, giving directions as to the dissection of the type-forms chosen in illustration. Further, being dissatisfied with anatomical nomenclature and classification generally, more especially with the terms at present in use in myology, he attempted a revision in this department.

As he proceeded with his task, however, he found that the labour, time, and knowledge necessary for carrying out so extensive a piece of work was too great, and that he had better relinquish his original idea and leave it for execution to more competent labourers.

But even after departing so far, and wisely as we think, from his first conception of what a student's text-book should be, he has found it necessary still further to withdraw from his original plan, and to excise much that he had written on anomalies of arrangement, various paragraphs on dissections which are out of the student's usual course to perform, and to reduce in quantity the sections on the practical applications of anatomy.

Had the author carried out his original idea of what a handbook for students and practitioners should be, he would have produced an encyclopædia of anatomy, and not a text-book for daily use.

But after all this renunciation of so much of the author's primary conception of what is required in a practical work on anatomy, sufficient is left to form a most voluminous treatise.

The volume before us extends to 7 I 9 large octavo pages. It comprises only the anatomy of the limbs and perinæum, and we are promised two additional volumes, each of between six and seven hundred pages, in order to complete the work.

It seems to us that the author even yet has not attained a proper idea of what the contents of a book should be, which, to use his own words, "is to be chiefly used while the student is dissecting." He has not sufficiently discriminated between the material that should find a place in a text-book of systematic anatomy and that which properly belongs to a practical treatise. We are quite in unison with him in the propriety of omitting all illustrations and detailed description of minute or microscopic anatomy. But we should have gone still further and cut out the historical sketch, the bibliography, the chapter on anatomical technics, which together would have subtracted between 60 and 70 pages from the volume. Also we should have condensed the descriptions and reduced in amount the sections on variations in the arrangements of the bones, muscles, and other soft parts.

A sketch of the rise and progress of anatomy, and a copious bibliography are not required by the student at the dissecting table. On the other hand they are both interesting and useful in a systematic treatise. The variations in arrangement, more especially in the muscular and vascular systems, which have been observed and recorded, are so multitudinous, that they would require a special treatise for their description. What the student has to deal with in his ordinary work, are the commoner departures from the usually described arrangements, such as a third head to the biceps muscle, the high division of the brachial artery, the variations in the place of origin of the obturator, the profunda, the circumflex arteries, and so on. These and such like ought to find a place in all works on practical anatomy, but the more unusual forms are best reserved for such special treatises as Macalister's Catalogue of Muscular Anomalies, or Quain's description of the Arterial System, to which the student, who is desirous of obtaining a more intimate acquaintance with variations in structure, ought to be referred.

A knowledge of anatomical technics also is undoubtedly of primary importance to professed anatomists. But is one student in five hundred ever called upon to inject a body, either with a preservative fluid, or with a coloured arterial or venous injection? This work is done for him either by the demonstrator, or by the practical assistant in charge of the rooms. To introduce therefore into a work intended for medical students generally an account of methods, which they are never required to carry out, seems to us to be uncalled for.

The author directs especial attention to the number and quality of the illustrations. As regards their quality, with a few exceptions they are artistically rendered. But we think they are far too numerous, and by their number, and the size of many of the cuts, they have largely contributed to the unwieldy bulk of this treatise. Too many illustrations in a book to be used at the dissecting table are apt to draw the student's attention away from his part, and to make him rely upon the pictorial representation rather than on his own efforts to display the organ or region in the subject itself.

In our judgment a handbook of practical anatomy ought to be of such a size, that the student can without inconvenience carry it to and from his work. The instructions for the order of the dissections should be clear and concise. The descriptions of the parts should not be too elaborate. The illustrations should be well selected, with a view to guide the student in the method of his work, and to show him what he has to look for, and where it has to be seen. This treatise fails to comply in many respects with these conditions, and much as we may commend the author for his industry and good intentions, we are afraid that he has produced a work which will have only a restricted field of usefulness.

\section{OUR BOOK SHELF}

Common British Insects. Selected from the Typical Beetles, Moths, and Butterflies of Great Britain. By the Rev. J. G. Wood, M.A., \&c. Pp. i.-284. 8vo. (London : Longmans, Green, and Co., 1882.)

AFTER glancing through this book the question uppermost in our mind is: Why does it exist? The highlyornamented cover, and the repeated title thereon, lead one 